\title{
Correlation of total ischemic time to creatinine serum level and resistive index value in kidney transplant
}

\author{
Putu Astri Novianti', \\ Gede Wirya Kusuma Duarsa², \\ Gede Andi Aditya ${ }^{3}$, \\ Anak Agung Gde Oka², \\ Kadek Budi Santosa², \\ I Wayan Yudiana ${ }^{2}$, \\ Pande Made Wisnu Tirtayasa ${ }^{2}$, \\ Ida Bagus Putra Pramana², \\ Yenny Kandarini ${ }^{4}$, \\ Wayan Sudana ${ }^{4}$, \\ Djodi Sidartha ${ }^{4}$, \\ Raka Widiana ${ }^{4}$ \\ 'General Surgery Department, Faculty of \\ Medicine, Udayana University-Sanglah General \\ Hospital, Denpasar, Bali-Indonesia \\ 2Urology Department, Faculty of Medicine, \\ Udayana University-Sanglah General Hospital, \\ Denpasar, Bali-Indonesia \\ ${ }^{3}$ Faculty of Medicine, Udayana University, \\ Denpasar, Bali-Indonesia \\ ${ }^{4}$ Nephrology Department, Faculty of Medicine, \\ Udayana University-Sanglah General Hospital, \\ Denpasar, Bali-Indonesia
}

Cite this article:

Novianti PA, Duarsa GWK, Aditya GA, Oka AAG, Santosa KB, Yudiana IW, Tirtayasa PMW, Pramana IBP, Kandarini Y, Sudana W, Sidartha D, Widiana R. Correlation of total ischemic time to creatinine serum level and resistive index value in kidney transplant. Neurologico Spinale Medico Chirurgico. 2020;3(2):26-3I. DOI: I0.36444/nsmc.v3i2.I09

Corresponding author:

Gede Wirya Kusuma Duarsa

Urology Department, Faculty of Medicine,

Udayana University-Sanglah General Hospital,

Denpasar, Bali, Indonesia

gwkduarsa@yahoo.com

\begin{abstract}
Background: The transient period when the kidney donor was extracted until being anastomosed (total ischemic time) will aggravate many putative molecular ischemic-reperfusion injury mechanisms. Several studies have reported the risk of delayed graft function development, which can be reflected by creatinine serum $(\mathrm{Cr})$ level and resistive index (RI) value. This study aims to determine the correlation of total ischemic time to $\mathrm{Cr}$ levels reduction in one-month posttransplantation and RI value.

Methods: This was a cross-sectional retrospective study involving subjects who underwent kidney transplantation in Sanglah General Hospital. In this study, the primary parameters were total ischemic time, Cr level, and RI value. The total ischemic time is calculated using a stopwatch intraoperatively. Cr level was obtained from blood examination, and RI value was obtained from the ultrasonography test. Data analysis was analyzed statistically using SPSS 24.0, and p $<0.05$ was considered significant.

Results: About 17 kidney transplant subjects were included in this study. The mean total ischemic time was 105 minutes and 43 seconds. There was an insignificant negative correlation between $\mathrm{Cr}$ level reduction and total ischemia time $(r=-0.36 ; p=0.89)$. An analysis of the correlation of total ischemic time and RI value, there was a linear correlation, but statistically insignificant $(r=0.11$; $\mathrm{p}=0.66)$.
\end{abstract}

Conclusion: Total ischemic time has a negative correlation with post-transplant creatinine serum level and a positive correlation with the post-transplant resistive index value, but these results are not statistically significant.

Keywords: Kidney transplantation, Ischemic time, Creatinine serum level, Resistive index

\section{Introduction}

The number of patients with end-stage renal disease (ESRD) is increasing every year. ${ }^{1}$ The broaden development in health facilities supports kidney transplantation as the best choice for ESRD therapy in terms of better survival rate and quality of life achievement. ${ }^{2}$ Many factors affect the success of kidney transplantation, included intraoperative factor. During surgery, the kidney graft will be exposed to the condition of ischemic time, where there is no blood flow to the graft. ${ }^{3}$ 
There are three potential periods for ischemic injury during a kidney transplant. First, the period before organ retrieval in the donor defined as "first warm ischemia time". Second, there is a period where the kidney graft is transported from the donor to the recipient in a cold solution, defined as cold ischemia time (CIT). Lastly by a period of second warm ischemia time (WIT) period during reanastomosis in the recipient, the kidney graft is taken out of cooling and reperfused by the recipient's blood. ${ }^{3}$

Many studies showed that long ischemic time duration would cause hypoxia of the graft tissue and increase the risk of ischemia and reperfusion injury (IRI) and delayed graft function (DGF). DGF is defined as a failure of the renal transplant to function immediately, with the need for dialysis in the first post-transplantation week. This can be reflected by a decrease of less than $25 \%$ of the serum creatinine level and high resistive index. ${ }^{3}$ However, studies showed controversial result and the magnitude of the failure risk was varied. Therefore, this study aims to determine the correlation of total ischemic time to creatinine serum levels reduction in one-month post-transplantation and resistive index value.

\section{Methods}

This study is an analytic cross-sectional study to determine the correlation of total ischemic time and creatinine serum level reduction in one-month post-transplantation and the resistive index values. All medical records of subjects underwent kidney transplantation procedure in Sanglah General Hospital from January 2016 to November 2019 were collected.

In Sanglah General Hospital, about 17 kidney transplantation procedures had been done. Kidney transplantation was carried out by a team consisting of urology, nephrology, anesthesiology, cardiology, pulmonology, gastroenterology, oral and dental specialists, psychiatry, and clinical nutrition. Patients with ESRD are screened as potential candidates for kidney transplantation. The patient and family members then provide a list of potential kidney donors. The recipient and donor have cleared all series of history taking, physical examination, and diagnostic tests such as complete blood tests, liver function tests, kidney function tests, electrolytes, urinalysis, serology tests (HIV, HBsAg, anti-HBs, anti-HBc, anti-HCV, CMV virus), chest X-ray, renal and urinary tract ultrasound, echocardiography, computed tomography (CT) angiogram, and tissue typing examination including $\mathrm{ABO}$ examination and human leukocyte antigen (HLA) cross match. In our center, all recipients receive kidneys from living donors. The donor and recipient underwent kidney transplantation at the same day.
In this study, the primary parameters were total ischemic time, serum creatinine level, and resistive index. The total ischemic time is calculated using a stopwatch intraoperatively. During surgery, there are three crucial periods of ischemic duration during kidney transplant surgery. The first, warm ischemic time, is the period when the kidney is retrieved from the donor. The second, cold ischemic time (CIT), is the period when the kidney is being placed in the ice or hypothermic condition for transportation. The third, second warm ischemic time (WIT), while the kidney is being anastomosed to the recipient. Then, the ischemic time was summed. The duration was interpreted as hours and minutes. Serum creatinine level was obtained from blood examination and resistive index values were obtained from ultrasonography test.

Data analysis was carried out using a statistical package of social sciences (SPSS) version 24.0. Descriptive analysis was used to provide an overview of the characteristics of the sample and the Shapiro-Wilk normality test. The quantitative variables were analyzed by means and standard deviation or medians, while the qualitative variables were analyzed as proportions. A bivariate analysis of the quantitative variables was performed using the Pearson correlation. A value of $\mathrm{p}<0.05$ was considered significant.

\section{Results}

About 17 kidney transplant procedures have been carried out at Sanglah Hospital from January 2016 to November 2019 with the characteristic of the samples in Table 1. Recipients consist of 14 males and three females. Based on the age, the mean recipient age is $31.09 \pm$ 7.33 years old, and the mean age of the donor is $49.65 \pm 9.93$ years old. All donors have the family-related pedigree to the patients (13 donors from mother, 1 donor from father, 3 donors from a sibling).

All data were normally distributed, thus could be analyzed parametrically (Table 2). The mean creatinine serum level decrease progressively after kidney transplant procedure (1 month after surgery: $1.36 \pm 0.37 \mathrm{mg} / \mathrm{dL}, 1$-day after surgery: $7.86 \pm 1.82 \mathrm{mg} / \mathrm{dL}$, baseline: $9.10 \pm 1.88 \mathrm{mg} / \mathrm{dL})$. The mean value of resistive index on posttransplantation day- 1 is $0.68 \pm 0.08$ and $0.65 \pm 0.05$ in the following month. After tabulated total ischemic time in 17 subjects, the mean time was 105 minutes and 43 seconds. The duration of $1^{\text {st }}$ WIT was 1 minute and 22 seconds, CIT was 44 minutes and 23 seconds, and $2^{\text {nd }}$ WIT was 59 minutes and 57 seconds. From all subjects, the longest duration of the $1^{\text {st }}$ WIT was 3 minutes 28 seconds, CIT was 109 minutes 34 seconds, and the $2^{\text {nd }}$ WIT is 88 minutes 52 seconds. 
Table 1. Characteristic of kidney transplant patients in Sanglah Hospital January 2016-November 2019

\begin{tabular}{lc}
\hline Characteristic & Value \\
\hline Age, year & Mean \pm SD \\
Recipient & $31.06 \pm 7.33$ \\
Donor & $49.65 \pm 9.93$ \\
Gender & $\mathrm{n}(\%)$ \\
Male & $14(82.4)$ \\
Female & $3(17.6)$ \\
Donor-recipient relationship & $\mathrm{n}(\%)$ \\
Mother & $13(76.5)$ \\
Father & $1(5.9)$ \\
Sibling & $3(17.6)$ \\
Ischemic time, mean & Minutes: seconds \\
Warm ischemic time I & $01: 22$ \\
Cold ischemic time & $44: 23$ \\
Warm ischemic time II & $59: 57$ \\
Total ischemic time & $105: 43$ \\
Creatinine serum (Cr), mg/dL & Mean \pm SD \\
Pre-transplantation & $9.10 \pm 1.88$ \\
Post-transplantation (day-1) & $7.86 \pm 1.82$ \\
Post-transplantation (1-month) & $1.36 \pm 0.37$ \\
Resistive index (RI) USG Doppler & Mean \pm SD \\
Post-transplantation (day-1) & $0.68 \pm 0.08$ \\
Post-transplantation (1-month) & $0.65 \pm 0.05$ \\
\hline &
\end{tabular}

Table 2. Results of the Shapiro-Wilk normality test

\begin{tabular}{lc}
\hline Variable & P-value \\
\hline Total ischemic time & 0.28 \\
Cr level reduction post-transplantation (1-month) & 0.27 \\
RI value post-transplantation & 0.98 \\
\hline
\end{tabular}

For bivariate analysis, a Pearson correlation test was done (Table 3). There was an insignificant negative correlation between serum creatinine level reduction and total ischemia time $(r=-0.36 ; p=$ 0.89). An analysis of the correlation of total ischemic time and resistive value, there was a linear correlation, but statistically insignificant $(r=$ $0.11 ; \mathrm{p}=0.66)$.

Table 3. Correlation test results between total ischemic time with a decrease in Cr one-month post-transplantation and RI value

\begin{tabular}{lcc}
\hline \multirow{2}{*}{ Variable } & \multicolumn{2}{c}{ Total ischemic time } \\
& R & P-value \\
\hline SCr level reduction post-transplantation (1-month) & -0.36 & 0.89 \\
RI value post-transplantation & 0.11 & 0.66 \\
\hline
\end{tabular}

\section{Discussion}

Kidney transplantation is recognized globally as the gold standard treatment of ESRD. Several studies show that kidney transplantation is associated with a significant reduction in long-term mortality risk and cardiovascular events, as well as clinically relevant improvements in quality of life. ${ }^{4,5}$ Complications that could occur after kidney transplantation procedure, such as vascular complications (renal artery or vein stenosis, arteriovenous fistula, pseudoaneurysm); urological complications (urine obstruction or leakage, accumulation of peri-transplant fluid such as hematoma, seroma, lymphocele, urinoma, abscess formation, distal ureteral ischemic necrosis) ${ }^{6}$; medical complications (anemia, hypertension, infection, graft rejection, malignancy). ${ }^{7}$ Delayed graft function is one of the most concerning complications, which is majorly reported to be affected by a longer ischemic time during surgery. Nevertheless, proper functioning of the graft is essential for patients to re-establish body homeostasis and thus benefit from receiving the transplant. The injury during low oxygen and the restoration of oxygen had been proposed to induce ischemiareperfusion injury (IRI). IRI in kidney transplantation could cause DGF and associated with episodes of acute rejection and progression to chronic allograft nephropathy. Alloantigen-independent inflammation plays an essential role in the pathogenesis of IRI. ${ }^{3}$

Intraoperatively, the transplanted kidney will be exposed to two different processes, WIT and CIT. Total ischemic time is a combination of WIT and CIT. The first WIT is defined by the time between clamping of the donor's artery and vein until the graft is preserved in cold storage. In this period, cell damage can occur due to decreased oxygen supply to cells with a consequent reduction of aerobic metabolism to an anaerobic route. ${ }^{3}$ Within the unoxygenated period, many putative molecular mechanisms happened in terms of ischemic injury. Ischemia causes a massive release of compounds called dangerassociated molecular patterns (DAMPs), such as heat shock proteins (HSP), fibronectin, hyaluronan fragments, high-mobility group box 1 (HMGB1) and heparin sulfate. DAMPs activate Toll-like receptor (TLR) 2, 4, 5, which act as pattern recognition receptors (PRR). The activation of PRR could provoke both the death signaling pathway and the production of proinflammatory cytokines and chemokines, such as TNF- $\alpha$, IL-1 $\beta$, IL-6, CCL2, MIP-2. This process accompanied by neutrophil and macrophage infiltration. Transduction of signals after TLR activation depends on MyD88 protein, resulting in activation of transcription factor NF- $\kappa \mathrm{B}$ with subsequent proinflammatory cytokines and chemokines. ${ }^{8,9}$ Besides macrophages and dendritic cells, tubular epithelial cells constitutively express TLR2 and TLR4, and this expression is increased during IRI. Kruger et al., showed that TLR4 expression was upregulated in deceased donor as compared to living donor kidneys. Furthermore, graft function was improved in recipients of kidneys carrying the loss-of-function TLR4 gene mutations. ${ }^{10}$

The second WIT is the period of vascular reanastomosis in the 
recipient; the graft is taken out of cooling and reperfused with the recipient's blood. Duarsa et al., reported a unique experience during vascular graft anastomosis in the recipient. There was massive iliac lymphadenopathy which surrounded the iliac artery and vein, so it was impossible to gain access for graft anastomosis. Extensive lymphadenopathy was performed which brought risk to possible vascular damage. The duration of operation was increased significantly by performing the lymphadenectomy. However, the procedure was carried out successfully. ${ }^{11}$ During the second WIT period, the oxygen supply is restored and a perfusion injury could happen.

Within 30-minutes after the reperfusion, neutrophils attach to peritubular capillaries and accumulate in kidney interstitium. Neutrophils aggravate kidney injury by producing reactive oxygen species (ROS), myeloperoxidase, and cytokines such as IL-17. Macrophages infiltrate the kidney just after neutrophils transmigrate into it. Macrophages stimulate chemokine synthesis in resident dendritic cells, then activate T-lymphocytes and recruit adaptive immune cells. Proximal tubule cells secrete pro-inflammatory cytokines (TNF- $\alpha$, IL-1 $\beta$, IL-6) and upregulate C-X-C motif chemokine three receptor (CXCR3) on their basement membrane to facilitate the penetration of inflammatory cells beyond the microvascular cuff. Once leukocytes penetrate proximal tubule cells, nicotinamide adenine dinucleotide phosphate (NADPH) oxidase in macrophages and myeloperoxidase in neutrophils create local free radical. Eventually, homeostasis disturbed, apoptosis being excessive, and tissue damage happened, resulting in tubular epithelial degeneration, tubular cell exfoliation, and then parenchyma injury. Siedlecki et al., stated that kidney transplant recipient with ligands to CXCR3 detected in the urine at higher risk for DGF post-transplant. ${ }^{9}$ Pathologic vasoconstriction also occurs due to preceding ischemic injury. Damaged vascular endothelium release endothelin (ET-1) and renal nitric oxide (NO) level increase to balance the vasoconstrictive effect of endothelin. NO induces vasodilatation at low concentrations. However, NO reacts with superoxide to produce ROS (peroxynitrite) at higher concentrations. ${ }^{9}$

The sign of the early phase of improper graft function is low glomerulus filtration rate (GFR), which can be indicated by a higher serum creatinine level. Adequate perfusion has a significant role in maintaining graft survival. Ischemia-induced hypoxia may impair graft microcirculation, leading to proximal tubular epithelial cell injury. ${ }^{12}$ The tubular damage results in impaired proximal sodium reabsorption. This impaired tubular transport of sodium activates tubular glomerular feedback (TGF) mechanism leading to increased afferent vasoconstriction and a concomitant decrease in GFR. ${ }^{13}$ RI is a physiological value that can measure the degree of resistance of renal and intrarenal vessels. RI is highly utilized to assess the graft function using Doppler ultrasonography. Many factors can increase RI, such as systemic factors (hypotension, age, heart rate), extrarenal factors (vascular stenosis, ureteral obstruction, allograft compression due to perinephric collection), and intrarenal factors (acute tubular necrosis, transplant rejection, and graft nephritis). Thus, the function of the kidney graft can be measured by RI value and creatinine serum level. In clinical studies reviews conducted by Tirtayasa et al., RI values are classified into low RI (RI < 0.57; 0.57-0.7; < 0.74; and 0.74-0.81) and high RI $($ RI > 0.7 and > 0.81). High RI values associated with DGF (42.8\%). RI also has a significant direct correlation with $\mathrm{Cr} .{ }^{14}$ Table 1 shows creatinine serum levels reduction in one-month post-transplant compared to pre-transplant and low RI values.

In this study, we showed that the mean creatinine serum level decreases progressively after kidney transplantation procedure. The mean value of resistive index before and after transplantation did not differ significantly. We also found that no significant statistical correlation between total ischemic time and creatinine level as well as the resistive index value. Regardless of that, the descriptive data showed that the longer the total ischemic time, the higher the serum creatinine level. This result differed from Nugroho et al., who showed a strong negative correlation between the length of the total ischemic time and the reduction in creatinine levels $(r=-0.44, \mathrm{p}=0.008){ }^{15}$ Simpkins et al., reported that prolonged CIT did not result in lower serum creatinine, increased acute rejection, or compromised allograft survival in any groups with $>2$-h CIT compared with the $0-2 \mathrm{~h}$ group. ${ }^{16}$ During the CIT period, cold preservation of the graft could slow anaerobic metabolism and its subsequent accumulation of metabolic waste products. However, it does not halt the consequences of cellular ischemia. ${ }^{17}$ Living-donor has the advantage in minimizing CIT compared to the deceased donor because transplantation procedure could be performed in sequential (use same operating room) or simultaneous (use different operating room) manner. Prudhomee et al., showed CIT and DGF were significantly higher in the sequential group than the simultaneous group, and CIT was a significant predictor of DGF. ${ }^{18}$ Several studies showed varied results about ischemic time (Table 4).

Despite reporting no differences in terms of renal function, it is important to note that the consequences of a long ischemic time are widely reported. There are many growing studies that addressed this issue regardless of its significance in the statistical calculation. Still, the descriptive analysis showed a negative effect of longer total ischemic 
time on renal function. Further study was needed for a more comprehensive analysis of this effect.

Table 4. Delayed graft failure risk in increasing ischemic time

\begin{tabular}{|c|c|c|}
\hline Study & Warm Ischemic Time (WIT) & Cold Ischemic Time (CIT) \\
\hline Heylen, 2017 & $\begin{array}{l}\text { DGF' risk increase } 1.1 \text { for every } \\
10 \text {-min increase. }{ }^{19}\end{array}$ & \\
\hline Tennankore, 2016 & $\begin{array}{l}\text { DGF's risk increased } 1.07 \text { fold } \\
\text { within } 20-30 \text { of WIT, } 1.13 \text { within } \\
30-40 \text { min, } 1.17 \text { within } 40-50 \\
\text { min, } 1.2 \text { within } 50-60 \text { min, and } \\
\text { higher than } 1.23 \text { for more than } 60 \\
\text { min. }^{20}\end{array}$ & \\
\hline Marzouk, 2013 & & $\begin{array}{l}\text { DGF's risk increased } 1.07 \text { times for } \\
\text { each increasing minute }(\mathrm{p}=0.001) \text {. } \\
\text { Duration of anastomosis } 29 \text { minutes } \\
\text { was also associated with a } 3.5 \text { fold } \\
\text { higher }\left(\mathrm{p}=0.001 \text { ) risk of DGF. }{ }^{21}\right.\end{array}$ \\
\hline Debout, 2015 & & $\begin{array}{l}\text { DGF's risk increased } 1.013 \text { for each } \\
\text { additional hour of CIT.22 }\end{array}$ \\
\hline Osband, 2016 & & $\begin{array}{l}\text { DGF's risk increased } 1.19 \text { times in } \\
\text { CIT beyond } 5-60 \text { minutes ( } \mathrm{p}=0.03 \text { ). } \\
\text { By } 60 \mathrm{~min} \text {, DGF incidence was } \\
27.8 \% \text {, and by } 120 \mathrm{~min} \text {, incidence } \\
\text { doubled to } 60 \% .{ }^{23}\end{array}$ \\
\hline Krishnan, 2016 & & $\begin{array}{l}\text { DGF's risk increased } 1.28 \text { for every } \\
\text { hour increase in CIT, } 1.93 \text { for CIT } \\
4-8 \mathrm{~h}^{24}\end{array}$ \\
\hline Rios, 2019 & & $\begin{array}{l}\text { DGF's risk increased } 2.06 \text { times for } \\
\text { CIT } 12-18 \text { hours and } 3.38 \text { for CIT } \\
\text { more than } 18 \text { hours. }{ }^{25}\end{array}$ \\
\hline
\end{tabular}

\section{Conclusion}

Total ischemic time has a negative correlation with posttransplant creatinine serum level and a positive correlation with the post-transplant resistive index value, but these results are not statistically significant.

\section{References}

1. Report of Indonesian Renal Registry, Perhimpunan Nefrologi Indonesia (PERNEFRI). $11^{\text {th }}$ Report of Indonesian Renal Registry 2018. https://www.indonesianrenalregistry.org/data/IRR\%202018.pdf

2. Supit T, Nugroho EA, Santosa A, et al. Kidney transplantation in Indonesia: An update. Asian $J$ Urol. 2019; 6(4): 305-11. DOI: 10.1016/j.ajur.2019.02.003

3. Requiao-Moura LR, Junior MSD, Matos AC, et al. Ischemia and reperfusion injury in renal transplantation: Hemodynamic and immunological paradigms. Einstein (Sao Paulo). 2015;13(1):129-35. DOI: 10.1590/S1679-45082015RW3161
4. Rabbat CG, Thorpe KE, Russel JD, et al. Comparison of mortality risk for dialysis patients and cadaveric first renal transplant recipients in Ontario, Canada. J Am Soc Nephrol. 2000;11(5):917-22. Available at: https://jasn.asnjournals.org/content/jnephrol/11/5/917.full.pdf

5. Tonelli M, Wiebe N, Knoll G, et al. Systematic review: Kidney transplantation compared with dialysis in clinically relevant outcomes. Am J Transplant. 2011;11(10):2093-109. DOI: 10.1111/j.16006143.2011.03686.x

6. Duarsa GWK, Oka AAG, Santosa KB, et al. Successful boari flap ureteroneocystostomy for distal ureteral necrosis after renal transplantation. Urol Case Rep. 2019;23:48-9. DOI: 10.1016/j.eucr.2018.12.004

7. Juliana IM, Loekman JS. Complications after renal transplantation. J Peny Dalam. 2007;8(1):79-91

8. Kezic A, Stajic N, Thaiss F. Innate immune response in kidney ischemia/reperfusion injury: Potential target for therapy. J Immunol Res. 2017;2017:6305439. DOI: 10.1155/2017/6305439

9. Siedlecki A, Irish W, Brennan DC. Delayed graft function in the kidney transplant. Am J Transplant. 2011;11(11):2279-96. DOI: 10.1111/j.16006143.2011.03754.x

10. Kruger B, Krick S, Dhillon N, et al. Donor toll-like receptor 4 contributes to ischemia and reperfusion injury following human kidney transplantation. Proc Natl Acad Sci USA. 2009;106(9):3390-5. DOI: 10.1073/pnas.0810169106

11. Duarsa GWK, Oka AAG, Santosa KB, et al. An unusual case of lymphadenopathy due to continuous ambulatory peritoneal dialysis becomes a challenge during renal transplantation. Urol Case Rep. 2019;25:100890. DOI: 10.1016/j.eucr.2019.100890

12. Chevalier RL. The proximal tubule is the primary target of injury and progression of kidney disease: Role of the glomerulotubular junction. Am J Physiol Renal Physiol. 2016;311(1):F145-61. DOI: 10.1152/ajprenal.00164.2016

13. Basile DP, Anderson MD, Sutton TA. Pathophysiology of acute kidney injury. Compr Physiol. 2012;2(2):1303-53. DOI: 10.1002/cphy.c110041

14. Tirtayasa PMW, Duarsa GWK, Situmorang GRH, et al. Association between early resistive index measurement and early graft function and long term-graft survival after kidney transplantation: An evidence-based cilinical review. Acta Med Indones. 2019;51(1):77-85. Available at: http://www.actamedindones.org/index.php/ijim/article/download/852/pdf

15. Nugroho EA, Hidayat A, Hidayat AT. Correlation between total ischemic time with creatinine level and urine production in kidney transplant: A single center report. The Open Urology \& Nephrology Journal. 2019;12:6671. DOI: $10.2174 / 1874303 X 01912010066$

16. Simpkins CE, Montgomery RA, Hawxby AM, et al. Cold ischemia time and allo-graft outcomes in live donor renal transplantation: is live donor organ transport feasible?. Am J Transpl. 2007;7(1):99-107. DOI: 10.1111/j.16006143.2006.01597.x 
17. van der Vliet JA, Warle MC. The need to reduce cold ischemic time in kidney transplantation. Curr Opin Organ Transplant. 2013;18(2):174-8. DOI: 10.1097/MOT.0b013e32835e2a08

18. Prudhomme T, Benoit T, Mittal S, et al. Living-donor kidney transplantation: Comparison of sequential and simultaneous surgical organizations. Int Urol Nephrol. 2020;52(5):865-76. DOI: 10.1007/s11255019-02366-0

19. Heylen L, Pirenne J, Samuel U, et al. The impact of anastomosis time during kidney transplantation on graft loss: A eurotransplant cohort study. Am J Transplant. 2017;17(3):724-32. DOI: 10.1111/ajt.14031

20. Tennankore KK, Kim JS, Alwayn IPJ, et al. Prolonged warm ischemia time is associated with graft failure and mortality after kidney transplantation. Kidney Int. 2016;89(3):648-58. DOI: 10.1016/j.kint.2015.09.002

21. Marzouk K, Lawen J, Alwayn I, et al. The impact of vascular anastomosis time on early kidney transplant outcomes. Transplant Res. 2013;2(1):8. DOI: $10.1186 / 2047-1440-2-8$
22. Debout A, Foucher Y, Trebern-Launay K, et al. Each additional hour of cold ischemia time significantly increases the risk of graft failure and mortality following renal transplantation. Kidney Int. 2015;87(2):343-9. DOI: 10.1038/ki.2014.304

23. Osband AJ, James NT, Segev DL. Extraction time of kidneys from deceased donors and impact on outcomes. Am J Transplant. 2016;16(2):700-3. DOI: 10.1111/ajt.13457

24. Krishnan AR, Wong G, Chapman JR, et al. Prolonged ischemic time, delayed graft function, and graft and patient outcomes in live donor kidney transplant recipients. Am J Transplant. 2016;16(9):2714-23. DOI: 10.1111/ajt.13817

25. Nieto-Rios JF, Ochoa-Garcia CL, Serna-Campuzano A, et al. Time of cold ischemia and delayed graft function in a cohort of renal transplant patients in a reference center. Indian $J$ Nephrol. 2019;29(1):8-14. DOI: 10.4103/ijn.IJN_162_18

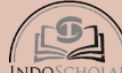

Articles published online under this model are officially published and can be cited and quoted using the DOI as the reference source. Neurologico Spinale Medico Chirurgico has a policy that changes will not be made after publication of an article without following accepted procedures for making corrections to the scientific record. The entire contents of the Neurologico Spinale Medico Chirurgico are licensed under the Creative Commons Attribution 4.0 International License. You are free to share - copy \& redistribute the material in any medium or format, adapt - remix, transform, and build upon the material for any purpose, even commercially. Under the following terms, you must give appropriate credit, provide link to the license, and indicate if changes were made. You may do so in any reasonable manner, but not in any way that suggests the licensor endorses you or your use. 